\title{
The Taylor Principle and Recent FOMC Policy
}

\author{
James B. Bullard
}

$\mathrm{T}$

here has been a good deal of discussion in the recent literature in monetary economics concerning the Taylor principle, named after John B. Taylor, professor of economics at Stanford University. In its broadest form, the principle is that a good monetary policy can be characterized by a target federal funds interest rate that moves more than one-for-one with inflation. ${ }^{1}$ According to a number of theories, such a policy maintains a desirable equilibrium for the economy in which inflation remains close to a target level, while failure to meet the principle may allow inflation, as well as other key variables, to deviate far away from target. How has the FOMC been faring over the past several years according to the criterion of the Taylor principle?

One simple way to consider this question is to compare movements in the FOMC's target federal funds rate to movements in inflation. The chart shows the effective federal funds rate for each month plotted along with the core personal consumption expenditures (core PCE) inflation rate, as measured from one year earlier. This measure of inflation excludes volatile food and energy prices, is widely cited in Federal Reserve commentary, and is less volatile than month-to-month readings. The federal funds rate has been rising consistently since June 2004, when the current Fed tightening cycle began. The core PCE inflation rate, on the other hand, was rising before June 2004, was generally flat over the following 18 months, and has recently been rising again.

If the Taylor principle holds, the target federal funds rate should move more than one-for-one with the inflation rate. During the first half of 2004, this was definitely not happening. The inflation rate was increasing, but the federal funds rate was in fact not changing at all, and so we conclude that the Taylor principle was not being followed during this period. Federal Reserve commentary at the time indicated that many on the FOMC were content to allow the inflation rate to rise during this period. This period is probably unusual since inflation was especially low.

During the period from July 2004 to the beginning of 2006, just the opposite pattern has held, according to these data. The core PCE inflation rate barely changed, on average, over this period. Indeed, the core PCE inflation rate was about 2.1 percent in July 2004 and was nearly identical, about 2.0 percent, in January 2006. Yet the federal funds rate was consis- tently increasing during this period. The Taylor principle was being met; in fact, many financial market participants expected the FOMC to pause in raising the federal funds rate target during the first half of 2006, in part because inflation remained close to 2.0 percent.

Yet when 2006 arrived, inflation began increasing once again. The core PCE inflation rate was about 2.4 percent in June, up approximately 40 basis points from February 2006. Is the Taylor principle still being met? It has become a closer call. The federal funds rate in February averaged about 4.5 percent, and by June it averaged nearly 5.0 percent, an increase of 50 basis points. Thus, according to these measures the Federal Reserve responded to increases in inflation with a coefficient of about 1.25 during this period, still enough to maintain the Taylor principle. But it is possible that continued increases in inflation coupled with a pause in the Fed's tightening cycle may cause the FOMC to violate the Taylor principle going forward.

\footnotetext{
${ }^{1}$ For a more detailed discussion of the Taylor principle, see Michael Woodford, "The Taylor Rule and Optimal Monetary Policy," American Economic Review, Papers and Proceedings, May 2001, 91(2), pp. 232-37.
}

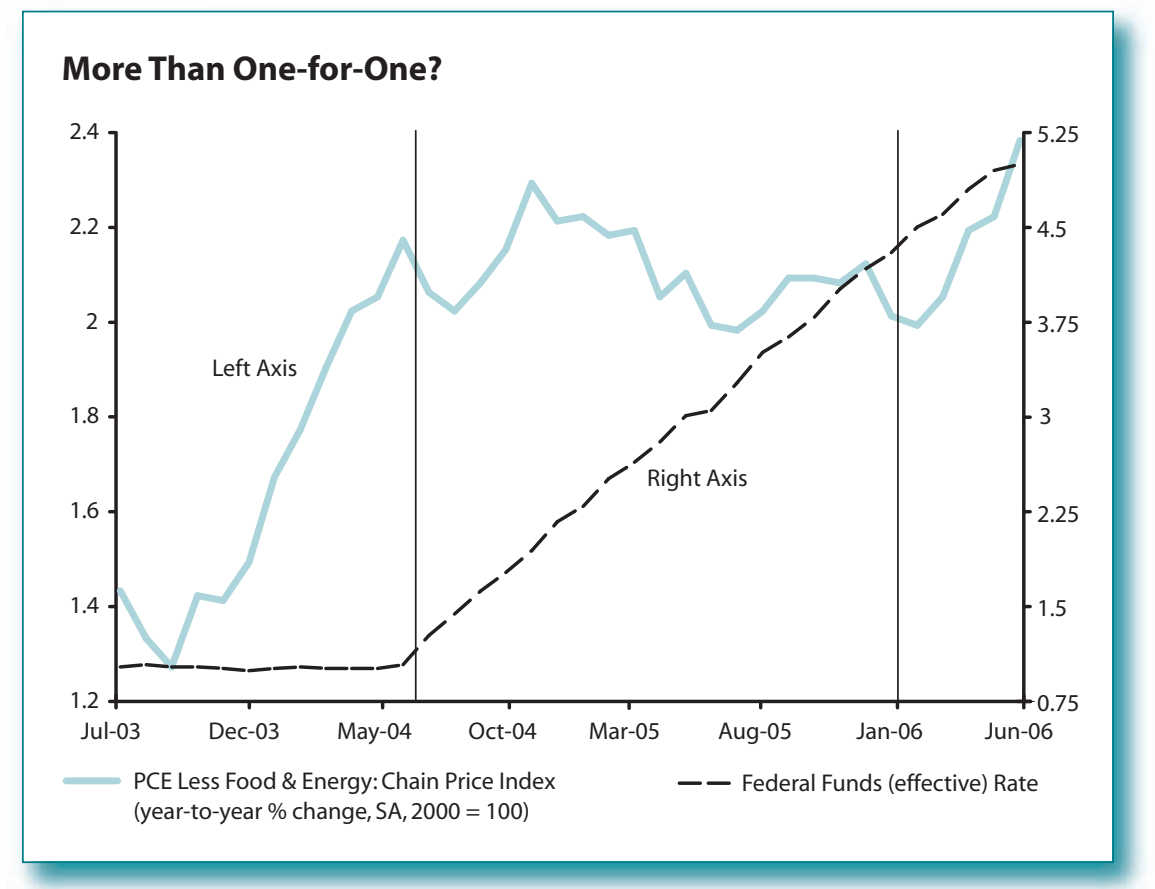

Views expressed do not necessarily reflect official positions of the Federal Reserve System. 